\title{
COMPAIXÃO, JUSTIÇA E DIREITOS HUMANOS: A TEORIA DAS CAPACIDADES EM NUSSBAUM
}

\author{
COMPASSION, JUSTICE AND HUMAN RIGHTS: THE THEORY OF CAPACITY IN \\ NUSSBAUM
}

\section{Marcia Andrea Bühring}

Doutora pela Pontifícia Universidade Católica do Rio Grande do Sul - PUCRS. Mestre pela Universidade Federal do Paraná - UFPR. Professora no PPGD UCS- Universidade de Caxias do Sul - RS e Professora da PUCRS. Escola de Direito. E-mail: mabuhrin@ucs.br

\section{Giovani Orso Borile}

Mestre em Direito Ambiental e sociedade pela UCS - Universidade de Caxias do Sul. Advogado. E-mail: goborile@ucs.br

Recebido em: 26/08/2018

Aprovado em: 13/08/2019

RESUMO: O objetivo é examinar a partir de Martha Nussbaum, a compaixão, a justiça e os direitos humanos, e como problema de pesquisa, é mostrar como a autora aborda o desenvolvimento das teorias das capacidades, como pressuposto de reconhecimento de determinado indivíduo em uma comunidade moral ou jurídica. Como justificativa da pesquisa, trazer como a autora pensa os direitos e a igualdade para os seres humanos no dever de cuidado, além de apontar a proteção do agir humano, que cada pessoa possa levar adiante, com autonomia, seu próprio projeto de vida. O método utilizado é o dialético, e o procedimento técnico é bibliográfico. Como conclusão, a verificação das "capacidades", que são classificadas em três categorias, básicas, internas e combinadas.

Palavras-chave: Teoria da Justiça. Direitos Humanos. Compaixão. Martha C. Nussbaum.

ABSTRACT: The aim is to examine from Martha Nussbaum, compassion, justice and human rights, and as a research problem, is to show how the author approaches the development of capacity theories, as a presupposition of recognition of a given individual in a moral or legal community. As justification of the research, bring as the author thinks the rights and equality for human beings in the duty of care, and points out the protection of human action, that each person can carry out, with autonomy, his own project life. The method used is dialectical, and the technical procedure is bibliographical. As a conclusion, the verification of the "capacities", which are classified into three categories, basic, internal and combined.

Keywords: Theory of Justice. Human rights. Compassion. Martha C. Nussbaum.

SUMÁRIO: Introdução; 1 Considerações Iniciais; 2 Compaixão e Humanidade: Justiça e Direitos Humanos a Partir de Nussbaum; 3 Capacidades e Direitos Humanos: Ponderações e Reflexões; Considerações Finais; Referências. 


\section{INTRODUÇÃO}

A influente intelectual dos Estados Unidos, Martha C. Nussbaum, é filósofa, e o reconhecimento de seu trabalho reune estudos antropológicos, psicanalíticos, sociológicos, sempre em busca da vida plena e próspera, foi professora em Harvard e atualmente, é professora na Universidade de Chicago, e, juntamente com Amartya Sen, fundou a Associação para o Desenvolvimento e Capacidade Humanos.

O problema de pesquisa, é mostrar como Martha C. Nussbaum aborda o desenvolvimento das teorias das capacidades, como pressuposto de reconhecimento de determinado indivíduo em uma comunidade moral ou jurídica. E como justificativa, trazer como a pensa a autora os direitos e a igualdade para os seres humanos no dever de cuidado.

O método utilizado é o dialético, baseado em Hegel, e o procedimento técnico é bibliográfico.

Dividiu-se o texto em três seções, sendo a primeira, com considerações inciais acerca da autora que iniciou seus estudos filosóficos dos grandes teóricos gregos e romanos, que no decorrer de seu amadurecimento intelectual, passou a desenvolver pesquisas relacionadas ao campo da justiça, do feminismo, das emoções e do desenvolvimento.

Na segunda seção, uma verificação da compaixão e humanidade, apontando a justiça e os direitos humanos a partir de Nussbaum, na qual aborda o desenvolvimento das "capacidades" como o pressuposto de reconhecimento de determinado indivíduo em uma comunidade moral ou jurídica. Na ideia de concessão aos sujeitos da possibilidade de desenvolverem suas capacidades, segundo um parâmetro de liberdade.

$\mathrm{Na}$ terceira seção abordar-se-a as capacidades e os direitos humanos, com algumas ponderações e reflexões, partindo-se da noção de que os direitos são assegurados quando garantidos às pessoas os meios para que sejam exercitados, quando fala-se em direitos humanos e em capacidades, o que se busca é, em suma, a implementação de um "roteiro emancipatório", que proteja o agir humano e assim permita que cada pessoa possa levar adiante, com autonomia, seu próprio projeto de vida.

Por fim, as "capacidades", podem ser classificadas em três distintas categorias: Básicas, são habilidades rudimentares para se levar uma vida digna, com as quais as pessoas vêm ao mundo; Internas: são estados da própria pessoa que se ligam à idéia de estado de maturidade; e Combinadas: resultam da combinação de capacidades internas com condições externas que possibilitam o exercício de uma funcionalidade.

\section{CONSIDERAÇÕES INICIAIS}

O pensamento de Nussbaum se inicia com o estudo filosófico dos grandes teóricos gregos e romanos, contudo, no decorrer de seu amadurecimento como pesquisadora passou a desenvolver pesquisas relacionadas ao campo da justiça, do feminismo, ${ }^{1}$ das emoções e também do desenvolvimento. ${ }^{2}$

Se anteriormente a proposta de justiça era a de raciocínio e deliberação internos a presente procura complementar, trazendo à tona o papel das emoções. ${ }^{3}$ Esse prognóstico já antecedia ao que

\footnotetext{
${ }^{1}$ NUSSBAUM, Martha C. Las mujeres y el desarrollo humano: el enfoque de las capacidades. Barcelona: Herder, 2002. p. 17 ss.

${ }^{2}$ Martha Nussbaum também possui estudos aprofundados acerca dos aspectos emocionais e sua comunicação com o meio social e político.

${ }^{3}$ Cf. NUSSBAUM, Martha C. El conocimiento del amor: ensayos sobre filosofía y literatura. Madrid: Antonio Machado Libros, 2016.
}

Revista de Direito Brasileira | Florianópolis, SC | v. 24 | n. 9 | p.86-102 |Set./Dez. 2019 
parece a iniciação ao papel das emoções ${ }^{4}$ no contexto da justiça, muito embora MacIntyre fosse contra as paixões descontroladas ou as chamadas paixões contrárias à razão ${ }^{5}$ ele apontou o amor $^{6}$ como predicado essencial e ressaltou apesar de tudo que o sentimento não é de todo desprezível desde que se trate do caso de alguém cuja razão e paixões são ordenadas retamente. ${ }^{7}$

Sendo assim, a suma do pensamento de MacIntyre pertinente à justiça e racionalidade se traduz na passagem onde ele afirma que a justiça é uma aplicação da razão à conduta e trata de como a vontade pode ser racionalmente dirigida para a conduta reta, ${ }^{8}$ destarte, a conexão com a perspectiva teorética de Nussbaum se dará de agora em diante a contar da temática das emoções ${ }^{9}$ proporcionada pelo legado de MacIntyre, dado aos já absorvidos conceitos anteriormente apresentados pelo autor.

As afeições ${ }^{10}$ protagonizam um papel imperativo e determinante no contexto da justiça e o apego à valores e emoções ${ }^{11}$ irá permitir que se complemente a ideia de raciocínio reflexivo ${ }^{12}$ numa transição que se alocará na compaixão ${ }^{13}$ e no estabelecimento de sentimentos para com o outro. ${ }^{14}$ Recordando-se de que Machado de Assis já alertava que "a falta de afeição é que traz a injustiça". 15

Do mesmo modo, o questionamento acerca de quem seriam os integrantes de uma comunidade moral já possibilita uma reflexão salutar acerca da temática de justiça, e nesse contexto Nussbaum se utiliza do conceito de capacidade para rediscutir a coexistência entre o homem e os animais.

\section{COMPAIXÃO E HUMANIDADE: JUSTIÇA E DIREITOS HUMANOS A PARTIR DE NUSSBAUM}

A datar do desenvolvimento de uma Teoria das Capacidades, a autora, advogando o argumento de que pelas capacidades assenta-se a constatação da admissão de direitos aos humanos, a ponto de constatar a existência de respeito para com eles não somente do ponto de vista social

\footnotetext{
${ }^{4}$ NUSSBAUM, Martha. Paisajes del pensamiento: la inteligencia de las emociones. Barcelona: Paidós, 2012. p. 5356.

${ }^{5}$ MACINTYRE, Alasdair. Justiça de quem? Qual racionalidade? São Paulo: Loyola, 1991. p. 216.

${ }^{6}$ Cf. LOBATO, Josefina Pimenta. Antropologia do amor: do Oriente ao Ocidente. Belo Horizonte: Autêntica, 2012. p. 09ss.

${ }^{7}$ MACINTYRE, Alasdair. Justiça de quem? Qual racionalidade? São Paulo: Loyola, 1991. p. 216.

${ }^{8}$ MACINTYRE, Alasdair. Justiça de quem? Qual racionalidade? São Paulo: Loyola, 1991. p. 216.

${ }^{9}$ NUSSBAUM, Martha C. Love's Knowledge: essays on Philosophy and Literature. New York: Oxford University Press, 1990. p. 261.

${ }^{10}$ Cf. ELSTER, Jon. Alquimias de la mente: la racionalidad y las emociones. Barcelona: Paidós, 2002.

${ }^{11}$ Victoria Camps propõe que as emoções tem um papel fundamental tanto na ética como na política e que devemos ser capazes de saber conter a emoção adequada para cada situação. Cf. CAMPS, Victoria. El gobierno de las emociones. Barcelona: Herder, 2011.

${ }^{12}$ NUSSBAUM, Martha C. La fragilidad del bien: fortuna y ética en la tragedia y la filosofía griega. Trad. de Antonio Ballesteros. Madrid: Visor, 1995. p. 343.

${ }^{13}$ ELSTER, Jon. Sobre las pasiones: emoción, adicción y conducta humana. Barcelona: Paidós, 2001. p. 13-21.

${ }^{14}$ Cf. SOLOMON, Robert C. Ética emocional: una teoría de los sentimientos. Barcelona: Paidós, 2007.

${ }^{15}$ ASSIS, Machado de. Histórias da meia noite. Rio de Janeiro: B. L. Garnier, Livreiro-Editor do Instituto Histórico, 1873. p. 214.
} 
mas de uma dignidade ${ }^{16}$ intrínseca, prospera uma teoria fundada na reconsideração dos indivíduos. ${ }^{17}$

A compreensão de quais padrões de fato se constituem indispensáveis para a composição de uma comunidade moral são indispensáveis para construção de um consenso sobre os titulares do agir justo.

Seguindo-se pelo critério da senciência ${ }^{18}$ o ente capaz de sentir prazer ou dor, suscetível à sentimentos, sequelas e sensações, poderia estar incluído na constituição da comunidade moral e, dessa forma, incorreria no dever de respeitar um outro agente moral, lembrando-se que ainda não se está falando em sujeito de direitos mas unicamente em agente moral. ${ }^{19}$

A capacidade de sentir dor e prazer é sem dúvida, uma condicionante que deve ser considerada não somente na condição de pacientes morais mas como agentes também, de sorte que o que define o indivíduo destinatário da justiça não é a racionalidade mas sim a condição de ser sensível e consciente do gozo, perigo ou desconforto.

De modo que o elemento condicional no caso é o fato de estar vivo, logo, existindo e não o de estar na vida, onde o simples fato de nascer ou tomar a existência e participar do contexto biótico já se torna uma condicionante, sendo inerência pura ao simples fato de estar vivo, consistindo-se esse o principal bem, a vida ou a existência.

Não existindo, portanto pressuposto mais adequado para os seres humanos, para que tenham seus interesses protegidos pela justiça e adequados aos sistemas sociais.

A tese de Nussbaum pretende o desenvolvimento das ditas "capacidades" como o pressuposto de reconhecimento de determinado indivíduo em uma comunidade moral ou jurídica.

Na ideia de concessão aos sujeitos da possibilidade de desenvolverem suas capacidades, segundo um parâmetro de liberdade, Nussbaum pensa os direitos e a igualdade para os seres humanos no dever de cuidado.

O fundamento seria o direito ao desenvolvimento das capacidades e não apenas questões sobre variações e similitudes biológicas ou justiça arbitrária, logo, parte-se para uma obrigação moral mais aprofundada. ${ }^{20}$

\footnotetext{
${ }^{16}$ Vide: BÜHRING, Marcia Andrea. Direitos Humanos e Fundamentais: Para além da Dignidade da Pessoa Humana, volume 1. Porto Alegre, RS: Editora Fi, 2014. p. 146. "Contemporaneamente dignidade é um valor, uma referência, é a matriz, o fundamento que identifica, qualifica e caracteriza o ser humano, enquanto ser dotado de direitos e deveres. A dignidade da pessoa humana é o principal direito fundamental constitucionalmente garantido no sistema brasileiro, fundamenta todo o sistema constitucional. Afirme-se: a dignidade é um direito inerente ao ser humano, é qualidade integrante e irrenunciável da própria condição humana, não pode e não deve ser retirada, pois é intrínseca, é atributo, é o esteio do Estado Democrático de Direito, é condição de democracia. Enquanto conceito - é aberto - que deve ser reinterpretado constantemente, levando-se em consideração, aspectos históricos, sociais, culturais, econômicos e jurídicos. O que não pode ocorrer é o desrespeito à dignidade, a exemplo de negar atendimento hospitalar em caso de necessidade-urgência."

${ }^{17}$ Amartya Sen já trabalhava com a perspectiva de capacidade, de modo que os estudos de Nussbaum e Sen se complementam. Cf. SEN, Amartya. Desenvolvimento como Liberdade. Tradução Laura Teixeira Motta. São Paulo: Companhia das Letras, 2000.

${ }^{18}$ Segundo síntese de Buglione e Schulte a "senciência significa sensibilidade e consciência ou percepção de si. A consciência é a capacidade de se perceber no mundo, um conceito mais amplo que o sentido de racionalidade nos moldes humanos". Cf. BUGLIONE, Samantha; SCHULTE, Neide Köhler. "Capacidades" como postulado para ampliar a comunidade jurídica e moral na proposta de Martha Nussbaum. R. Inter. Interdisc. INTERthesis, Florianópolis, v.10, n.1, p. 212-236, Jan./Jul. 2013. p. 215.

${ }^{19}$ FELIPE, Sonia T. Agência e paciência moral: razão e vulnerabilidade na constituição da comunidade moral. Ethic@ - Revista Internacional de Filosofia Moral, Florianópolis, v. 6, n. 4, 2007. p. 72.

${ }^{20}$ Nussbaum reproduz bem a lista de capacidades, no caso dos humanos, e aponta seus respectivos correspondentes, veja-se lista adaptada:

1. Vida: habilidade para viver até o final de uma vida humana de duração normal; não morrer prematuramente, ou antes que a vida se torne tão reduzida a ponto de não valer mais a pena viver;

2. Saúde Física: habilidade para ter uma boa saúde (incluída a saúde reprodutiva); estar adequadamente nutrido; ter moradia adequada;
}

Revista de Direito Brasileira | Florianópolis, SC | v. 24 | n. 9 | p.86-102 |Set./Dez. 2019 
Sendo assim, observa-se que em relação aos seres humanos, o dever de respeito e consideração decorre não somente de um valor moral ou estima da dignidade do sujeito passivo, o destinatário que sofre ação, mas sim de uma nova moralidade do agente proativo consubstanciador do ato justo.

O desenvolvimento das capacidades em Nussbaum, seria portanto o postulado capaz de fundamentar os direitos humanos ${ }^{21}$ e, consequentemente, a razão de se dever respeito a eles, de modo que os humanos possam integrar como personagens sua teoria da justiça. ${ }^{22}$

Consideram-se as capacidades como elementos inerentes ao sujeito que vive, mas que todavia se cruzam e se sobrepõem em relação ao próprio sujeito e aos outros, ${ }^{23}$ e em face à essa diversidade de capacidades singulares, analisa-se as competências inatas dos humanos como ponto

3. Integridade física: poder livremente se mover de um lugar a outro; estar seguro contra abuso violento, incluindo abuso sexual e violência doméstica; ter oportunidade de obter satisfação sexual e escolha no que se refere à reprodução; 4. Sentidos, imaginação e pensamento: poder usar os sentidos, imaginar, pensar e raciocinar - e fazer essas coisas de "forma realmente humana", de modo informado e refinado por uma educação adequada, incluindo, mas de forma alguma limitado a, alfabetização e treinamentos matemáticos e científicos básicos. Poder usar a imaginação e o pensamento juntamente com o experimento e a produção de trabalhos e eventos de sua própria escolha, religiosos, literários, musicais, e assim por diante. Poder usar a própria mente de forma protegida pela liberdade de expressão, tanto em relação ao discurso político como artístico e liberdade de exercício da religião. Poder ter experiências prazerosas e evitar dor não benéfica.

5. Emoções: poder estar conectado a coisas e pessoas fora de nós mesmos; poder amar aqueles que têm carinho e nos amam e sofrer pela sua ausência; em geral, amar, sofrer, experimentar gratidão duradoura e raiva justificada. Não ter o desenvolvimento emocional interrompido por medo ou ansiedade (dar suporte a esta capacidade significa dar suporte a formas de associação humana que podem se mostrar cruciais ao seu desenvolvimento).

6. Razão prática: poder formar uma concepção do bem e engajar em reflexões críticas sobre o planejamento de sua própria vida (Isso permite a proteção da liberdade de consciência e da prática da religião).

7. Afiliação: (A) poder viver com e entre outros, reconhecer e mostrar preocupação por outros seres humanos; engajarse em várias formas de interação social; poder imaginar a situação dos outros. (Proteger essa capacidade significa proteger instituições que constituem e nutrem estas formas de afiliação, e também proteger a liberdade de assembléia e o discurso político). B) dispor das bases sociais para o auto-respeito e não- humilhação; poder ser tratado como um ser humano digno cujo valor é igual ao dos outros. (Isso permite a previsão de não-discriminação com base na raça, sexo, orientação sexual, etniticidade, casta, religião, origem nacional.)

8. Outras espécies: poder viver com preocupação pelos e relacionando-se com animais, plantas e com o mundo da natureza;

9. Brincar: poder rir, brincar e desfrutar de atividades recreativas.

Controle sobre o ambiente: (A) Político: poder participar efetivamente das escolhas políticas que governam sua própria vida; ter o direito de participação política e proteções sobre discurso e associação; (B) Material: - poder ter propriedade (ambos, terra e bens móveis), ter direitos de propriedade em igualdade de condições com os demais; ter o direito de procurar emprego em igualdade de condições com os demais; estar livre de buscas e apreensões sem mandato. No trabalho, poder trabalhar como um ser humano, exercitando a razão prática e estabelecendo relações dotadas de sentido e mútuo reconhecimento com os outros trabalhadores. (Cf. NUSSBAUM, Martha C. Fronteiras da justiça: deficiência, nacionalidade, pertencimento à espécie. Trad. de Susana de Castro. São Paulo, 2013. p. 91.)

${ }^{21}$ Outro argumento que por nós será sustentado mais a frente é que "a razão para defender que os não-humanos tenham direitos próprios e inerentes (ou direitos subjetivos, em um jargão mais jurídico) é que isso garante a ação de exigir (exigibilidade) respeito aos interesses do sujeito de direitos, através de um guardião legítimo, mesmo que o sujeito não tenha capacidade reivindicatória, tal qual ocorre com crianças ou com pessoas sem capacidade civil". Cf. BUGLIONE, Samantha; SCHULTE, Neide Köhler. "Capacidades" como postulado para ampliar a comunidade jurídica e moral na proposta de Martha Nussbaum. R. Inter. Interdisc. INTERthesis, Florianópolis, v.10, n.1, p. 212-236, Jan./Jul. 2013. p. 225.

22 BUGLIONE, Samantha; SCHULTE, Neide Köhler. "Capacidades" como postulado para ampliar a comunidade jurídica e moral na proposta de Martha Nussbaum. R. Inter. Interdisc. INTERthesis, Florianópolis, v.10, n.1, p. $212-$ 236, Jan./Jul. 2013. p. 224.

${ }^{23} \mathrm{Na}$ perspectiva de Sen "a capacidade de uma pessoa consiste nas combinações alternativas de funcionamentos cuja realização é factível com ela. Portanto, a capacidade é um tipo de liberdade: a liberdade substantiva de realizar combinações alternativas de funcionamentos ". Cf. SEN, Amartya. Desenvolvimento como liberdade. São Paulo: Companhia de Letras, 2013. p. 10. 
referencial para repensar indivíduos de um outro contexto como ampliação do leque de destinatários de justiça, atribuindo-se certa universalização da comunidade moral. ${ }^{24}$

A proteção fundada na ideia de capacidade, por Nussbaum defendida, propaga a necessidade de oportunização de condições para o ente desenvolver algo que lhe é próprio, inerente, inato.

Isto se traduz na viabilização do modus operandi de cada ser segundo a sua própria natureza, ou seja, o homem como ser social e político precisa exercitar algo que lhe é intrínseco, como o direito ao voto e à participação pública, se o homem possui a predisposição à racionalidade, da qual tanto gaba-se e constitui motivo de sua proeminência, algo deverá ser feito quanto a isso, pois segundo a teoria das capacidades, é seu direito ter acesso à educação, ensino e aprendizagem. E sucessivamente se seguem diversos exemplos, dado que a capacidade estaria relacionada à potencialidades de cada indivíduo independentemente de classe, sexo ou raça.

Dessa forma, a teoria de justiça apresentada por Nussbaum dá a entender que o destinatário de justiça tem seu direito firmado não no que ele é ou se constitui mas também pelo que ele pode ser, suas potencialidades. Sendo assim, afirma ainda que

A capacidade de sentir não é a única coisa que importa para a justiça básica, mas parece plausível considerar a posse da capacidade de sentir como uma capacidade mínima para pertencimento na comunidade de seres que possuem direitos básicos de justiça. [...] Dado o fato de que prazer e dor não são as únicas coisas com valor intrínseco para o enfoque das capacidades, o enfoque, estritamente falando, não deveria dizer que a capacidade de sentir prazer e dor é uma condição necessária para se atribuir status moral a uma criatura. Ao contrário, deveríamos adotar um enfoque disjuntivo: se uma criatura possui ou tem a capacidade de prazer e dor, ou a capacidade de raciocínio e assim por diante (devemos acrescentar lazer, uso de ferramentas e outros), então essa criatura possui uma posição moral. ${ }^{25}$

Portanto, a justiça é encontrada no direito de prosseguimento das capacidades como forma de garantia das potências possíveis, dado que os critérios para consideração das dinâmicas de reconhecimento dos direitos de cada ente serão fundados no respeito à suas particularidades e sua "posição moral". ${ }^{26}$

Outrossim, em face ao fato de que o homem é detentor de "capacidade de raciocínio", ${ }^{27}$ deve-se abster de violar as capacidades dos indivíduos, ${ }^{28}$ fazer o mal, aqui chamado de prestações negativas, pretendendo-se também fazer o bem, prestações positivas, traduzidos na garantia de justiça e viabilização de prescrições e cuidados frente ao desenvolvimento de cada indivíduo, como por exemplo a manutenção do meio ambiente e equilíbrio ecológico atingindo a legislação e políticas públicas. ${ }^{29}$

\footnotetext{
${ }^{24}$ BUGLIONE, Samantha; SCHULTE, Neide Köhler. "Capacidades" como postulado para ampliar a comunidade jurídica e moral na proposta de Martha Nussbaum. R. Inter. Interdisc. INTERthesis, Florianópolis, v.10, n.1, p. 212236, Jan./Jul. 2013. p. 226.

${ }^{25}$ NUSSBAUM, Martha C. Fronteiras da justiça: deficiência, nacionalidade, pertencimento à espécie. Trad. de Susana de Castro. São Paulo, 2013. p. 444.

${ }^{26}$ NUSSBAUM, Martha C. Fronteiras da justiça: deficiência, nacionalidade, pertencimento à espécie. Trad. de Susana de Castro. São Paulo, 2013. p. 444.

${ }^{27}$ NUSSBAUM, Martha C. Fronteiras da justiça: deficiência, nacionalidade, pertencimento à espécie. Trad. de Susana de Castro. São Paulo, 2013. p. 444.

${ }^{28}$ NUSSBAUM, Martha C. Capacidades como Titulaciones Fundamentales: Sen y la Justicia Social. Bogotá, Colombia: Universidad del Externado de Colombia, 2005. p. 09ss.

${ }^{29}$ Vide: BÜHRING, Marcia Andrea. Direitos Humanos e Fundamentais: Para além da Dignidade da Pessoa Humana, volume 1. Porto Alegre, RS: Editora Fi, 2014. p. 145. "Os direitos de defesa, também são chamados de direitos negativos, devem ser assegurados, segundo ditame constitucional, pelo Estado e não devem ser violados por esse, a exemplo do direito de ir e vir, de manifestação, associação etc. Já os direitos de prestação, também chamados de

Revista de Direito Brasileira | Florianópolis, SC | v. 24 | n. 9 | p.86-102 |Set./Dez. 2019
} 
Segundo a perspectiva das capacidades o homem têm direitos, como prestações de justiça que impossibilitem a violação da sua integridade biológica e psíquica, entenda-se aqui qualquer forma de lesão física, como ferimentos e danos materiais, e lesões psicológicas, como stress, medo e ansiedade à eles incutidas como formas prejudiciais de tratamento. ${ }^{30}$

Assim, a perspectiva de equidade que permeia vários campos teóricos e diversas teorias de justiça, em Nussbaum prevê para os não-humanos a sua introdução como parte na concepção política de forma a estar estruturada no comprometimento de tratá-los com justiça e em garantir o desenvolvimento de suas capacidades.

Constata-se, por assim dizer, que as concepções de Nussbaum se constituem acepções fundamentais no campo das teorias de justiça, possibilitando a construção de novas formulações de dignidade e ambientalismo "enquanto catalisadora de emoções racionais, salientando suas contribuições para a racionalidade pública", ${ }^{31}$ e sustentação de uma nova teoria da justiça.

\section{CAPACIDADES E DIREITOS HUMANOS: PONDERAÇÕES E REFLEXÕES}

O enfoque das capacidades consiste na concepção substantiva de algumas habilidades centrais e oportunidades, principalmente incluindo oportunidades de escolha e atividade que possibilita comparações da qualidade de vida entre sociedades e serve como modelo para ser usado ao se perguntar em que medida uma sociedade assegura um mínimo de justiça a seus cidadãos. ${ }^{32}$

Trata-se de abordagem que permite às pessoas fazer suas próprias escolhas baseadas em suas diferentes concepções de uma boa vida, ${ }^{33}$ na medida em que foca na provisão de um conjunto básico mínimo de oportunidades e liberdades - vendo assim a vida das pessoas de forma separada e distinta. ${ }^{34}$

direitos positivos, (tem natureza programática, mas não meramente programática) de exigirse do Estado o seu cumprimento, a exemplo do direito a educação, saúde, previdência, trabalho.”

${ }^{30}$ Desse modo "Martha Nussbaum constrói sua teoria a partir da lógica jurídica, mas inova. Traz para o campo da filosofia a teoria do desenvolvimento das capacidades fazendo, assim, com que a liberdade seja, mesmo para animais não-humanos, o objeto principal de valor. Liberdade aqui como a possibilidade legítima e legal de desenvolver suas capacidades. Assim, respeitar a natureza, permitir ser quem somos, é a pedra angular do postulado proposto por ela. Ela busca ir além da abordagem antropocêntrica do desenvolvimento das capacidades, estendendo-a para nãohumanos. Com isso, ela espera ter uma série de princípios políticos, básicos e mapeados, que venham a orientar a legislação e a política pública voltadas para humanos e não-humanos. A autora desenvolve, assim, uma lista na qual conceitua as capacidades humanas que considera centrais, e desenvolve um parâmetro para os não-humanos. O ponto controverso de sua teoria está quando a autora afirmar que as diferentes formas de vida, que têm capacidades mais complexas a serem prejudicadas, tendem a sofrer mais e sofrer diferentemente os danos. Nesse momento ela cria uma espécie de hierarquia especista e permite até argumentos em prol do bem-estarismo. Isso porque os exemplos trazidos por ela operam a partir de uma lógica antropocêntrica, mesmo quando ela diz tentar evitá-la. Mas é fato que Nussbaum traz uma nova lupa para pensar um tema delicado, complexo e fundamental. Se o futuro reserva espaço para a coerência e práticas verdadeiramente abolicionistas não sabemos, porém, cabe aos pensadores de agora o dever de reinventar suas próprias teorias de forma que justiça não se confunda com pleonexia". Cf. BUGLIONE, Samantha; SCHULTE, Neide Köhler. "Capacidades" como postulado para ampliar a comunidade jurídica e moral na proposta de Martha Nussbaum. R. Inter. Interdisc. INTERthesis, Florianópolis, v.10, n.1, p. 212-236, Jan./Jul. 2013. p. 233.

${ }^{31}$ SILVESTRE, Ana Carolina Faria. As emoções racionais e a realização prática do direito à luz da proposta de Martha Nussbaum: o papel das obras literárias e das emoções racionais no processo de tomada de decisão judicial. Revista de Estudos Jurídicos, Franca-SP, a. 15, n. 22, 2011. p. 287-288.

${ }^{32}$ NUSSBAUM, Martha C. Frontiers of Justice: Disability, Nationality e Species Members. Harvard University Press, 2007. p. 74.

${ }^{33}$ NUSSBAUM, Martha C. The Supreme Court Term 2006 - Foreword: Constitutions and Capabilities: "Perception" against Lofty Formalism. Harvard Law Review. p. 17.

${ }^{34}$ NUSSBAUM, Martha C. The Supreme Court Term 2006 -Foreword: Constitutions and Capabilities: "Perception" against Lofty Formalism. Harvard Law Review. Disponível em: https://cdn.harvardlawreview.org/wpcontent/uploads/pdfs/nussbaum.pdf. Acesso em: 25 maio 2018. p. 20.

Revista de Direito Brasileira | Florianópolis, SC | v. 24 | n. 9 | p.86-102 |Set./Dez. 2019 
É, portanto, nas palavras de Robeyens, uma ampla moldura normativa que permite a avaliação e o alcance do bem-estar individual e de arranjos sociais, bem como a elaboração de políticas públicas e a realização de mudanças sociais, tendo como ponto focal a plena realização dos seres humanos. ${ }^{35}$

A compreensão da conceituação utilizada por Nussbaum não é tarefa fácil, seja em razão de problemas de tradução de obras estrangeiras para o português, ou da complexidade das circunstâncias, condições e conteúdos que se pretendem incluir na acepção dos termos capacidades (capabilities) e funcionalidades (functionings), desafio este que pretende-se vencer ao longo do trabalho.

Outra importante observação prévia acerca desses dois conceitos é que, dada a intrínseca relação que mantêm entre si, sua compreensão se mostra mais efetiva quando compreendidos em conjunto, razão pela qual tal critério de análise é adotado no presente trabalho.

A expressão capability ou capacidade ${ }^{36}$ foi inicialmente empregada por Amartya Sen ao explorar uma abordagem particular de bem-estar e vantagens, que levava em consideração a habilidade das pessoas para praticar atos ou alcançar estados físicos e psicológicos que elas valorizavam, ou seja, para indicar combinações alternativas de coisas que uma pessoa é capaz de fazer ou de ser. ${ }^{37}$

São potencialidades ou liberdades substantivas de que dispõem os indivíduos para que possam exercitar essas diversas formas de ser e de viver, fazendo aquilo que mais valorizam em sua vida.

Nessa direção, em sendo a vida das pessoas entendida como uma combinação de vários modos de ser e de fazer, por functionings, ou, como traduziu-se, funcionalidades, entende-se essas diversas coisas que uma pessoa pode querer ser, ter e fazer no processo de condução de sua própria vida. São esses diversos viveres e fazeres que tem-se razão para valorizar e que permitem definir os próprios caminhos.

Uma pessoa extremamente religiosa pode, por opção, não ficar bem nutrida na medida em que valoriza jejuar; outra pode, por quaisquer razões, levar uma vida celibatária ao invés de outra dotada de expressão sexual; uma terceira, mesmo dispondo de excelentes condições financeiras, pode preferir trabalhar de forma exacerbada, a gozar de lazer e recreação. ${ }^{38}$ Todos esses diferentes modos de conduzir a própria vida refletem um conjunto de funcionalidades.

Esses aspectos da realização humana variam em grau de complexidade, podendo em seu nível mais elementar representar, por exemplo, a vontade de sobreviver, de estar vestido, bem nutrido e livre de doenças e, numa instância superior e seguramente mais complexa envolver noções de auto-respeito, autonomia pessoal e preservação da dignidade humana. ${ }^{39}$

Os conceitos de capacidades e funcionalidades caminham juntos. São como duas faces de uma mesma moeda, que não se confundem, porque se vinculam por meio de uma relação de causalidade as capacidades correspondem a um potencial para exercício a uma liberdade no sentido

\footnotetext{
${ }^{35}$ Cf. REICHER, Stella Camlot. Capacidades e direitos humanos: uma análise conceitual sob a ótica de Martha Nussbaum. 2009. Tese de Doutorado. Universidade de São Paulo. 2009.

${ }^{36}$ A expressão refere-se ao sentido de ter potencial; estar apto a alguma coisa.

${ }^{37}$ NUSSBAUM, Martha C. Capability and Well-Being. In: NUSSBAUM, Martha C.; SEN, Amartya. (Orgs.). The Quality of Life. Oxford: Clarendon Press, 1993. p. 30.

${ }^{38}$ NUSSBAUM, Martha C. Women and Human Development: the Capabilities Approach. Cambridge: Cambridge University Press, 2001. p. 87.

${ }^{39}$ REICHER, Stella Camlot. Capacidades e direitos humanos: uma análise conceitual sob a ótica de Martha Nussbaum. 2009. Tese de Doutorado. Universidade de São Paulo. 2009. p. 40.
} 
substantivo, ou um poder agir necessário para que cada indivíduo possa atingir as mais diversas formas de ser e de fazer as funcionalidades. ${ }^{40}$

Para ilustrar melhor essa relação entre capacidades e funcionalidades, veja-se a seguinte situação: se o que alguém busca em sua vida é sentir-se bem nutrido (funcionalidade) é necessário que esse mesmo alguém disponha de comida (bem/recurso) e da capacidade ou habilidade para poder livremente comer quando melhor lhe aprouver.

Agora imagine-se que esse alguém é uma pessoa com tetraplegia. Impossibilitada de se movimentar livremente, embora dispondo de alimentos (recursos) e querendo sentir- se bem nutrida (funcionalidade) essa pessoa não dispõe de uma habilidade física ou deste potencial que lhe permitiria comer sozinha, razão pela qual necessita de alguma ajuda técnica ou de outra pessoa que lhe auxilie nessa tarefa.

Em não dispondo da capacidade para se valer do alimento disponível (recurso) por si só, e no momento em que bem quiser, o sentir-se bem-nutrida - ou seja, o alcance dessa funcionalidade - passa a não mais depender da vontade ou do livre agir do indivíduo. Nessa situação, é possível afirmar que essa pessoa encontra-se, portanto, limitada em sua liberdade, pois não consegue de forma independente conduzir sua vida como deseja. No entanto, esse exercício da liberdade e da autonomia pode ser desde logo restaurado, se esta pessoa puder contar com o auxílio de alguém que lhe ajude a se alimentar, pois assim, certamente poderá, quando assim lhe aprouver, comer e sentir-se satisfeita, mesmo não dispondo do potencial físico necessário para fazê-lo por sua conta.

Com este exemplo fica claro que para atingir determinadas funcionalidades, para além de ter acesso a bens e recursos, é necessário que os indivíduos tenham potencial habilidade de se valer destes, ou seja, que tenham plena capacidade ou ampla liberdade para usufruí-los quando assim quiserem. $^{41}$

Portanto, se há enfoques que se valem da utilidade pessoal (prazer, felicidade, satisfação de desejos), da opulência (renda per capita, bens, riqueza), da avaliação de liberdades negativas (satisfação procedimental de direitos de liberdade ou não- interferência) ou da igualdade, nesta abordagem, é esse conjunto de capacidades individuais - enquanto instrumental necessário à realização das mais diversas formas de ser e de fazer - que serve de elemento fundamental à avaliação do desenvolvimento e da qualidade de vida das pessoas. ${ }^{42}$

Partindo da noção de que os direitos são assegurados quando garantidos às pessoas os meios para que sejam exercitados, Nussbaum afirma que os principais direitos que se devem assegurar às pessoas são, na realidade, capacidades, ou seja, potenciais para o seu exercício, e não funcionalidades - ou o próprio exercício do direito.

E isso porque, conforme já tive-se a oportunidade de mencionar, quando fala-se em direitos humanos ${ }^{43}$ e em capacidades, o que se busca é, em suma, a implementação de um "roteiro

\footnotetext{
${ }^{40}$ REICHER, Stella Camlot. Capacidades e direitos humanos: uma análise conceitual sob a ótica de Martha Nussbaum. 2009. Tese de Doutorado. Universidade de São Paulo. 2009. p. 40.

${ }^{41}$ REICHER, Stella Camlot. Capacidades e direitos humanos: uma análise conceitual sob a ótica de Martha Nussbaum. 2009. Tese de Doutorado. Universidade de São Paulo. 2009. p. 42.

${ }^{42}$ NUSSBAUM, Martha C. Capability and Well-Being. In: NUSSBAUM, Martha C.; SEN, Amartya. (Orgs.). The Quality of Life. Oxford: Clarendon Press, 1993. p. 30.

${ }^{43}$ Vide: BÜHRING, Marcia Andrea. Direitos Humanos e Fundamentais: Para além da Dignidade da Pessoa Humana, volume 1. Porto Alegre, RS: Editora Fi, 2014. p. 144 “Os direitos humanos são de cunho internacional, são os direitos inerentes a todo ser humano, são válidos para todos os povos, em todos os tempos e termos, cuja Declaração Universal de 1948, representa o grande marco da consagração dessa universalização. Já os direitos fundamentais são de cunho nacional, são direitos garantidos, especificados e limitados no âmbito da Constituição Federal brasileira de 1988, (sendo por exemplo) o direito a saúde ao mesmo tempo um direito humano e também fundamental."
}

Revista de Direito Brasileira | Florianópolis, SC | v. 24 | n. 9 | p.86-102 |Set./Dez. 2019 
emancipatório", que proteja o agir humano e assim permita que cada pessoa possa levar adiante, com autonomia, seu próprio projeto de vida.

É por este motivo que conceder capacidades não significa de forma alguma exigir que venham a ser utilizadas.

Parece portanto, que a melhor forma de compreender o termo capabilities é de fato como capacidades ou potenciais cujo poder latente de exercício fica à disposição das pessoas, a fim de que possam usufruí-las de acordo com sua vontade.

É interessante notar ainda que a doutrina se utiliza das noções de capacidades e funcionalidades com sentidos diversos - o que não significa que tais entendimentos sejam excludentes, senão veja-se.

Sen, dentro do que chama "perspectiva de liberdade", sugere que a liberdade humana é o bem geral que se deve perseguir e que as capacidades são instâncias desse bem. ${ }^{44}$ Nesse sentido, emprega o conceito de capacidade em dois sentidos diversos e complementares, quais sejam: capacidade enquanto liberdade de agente (agency freedom) - nesse sentido, trata-se da liberdade para fazer acontecer as realizações que valoriza e tenta produzir, concepção que reflete a liberdade de escolha das pessoas entre diferentes formas de viver (p. ex.: uma pessoa que dispõe de alimentos e resolve jejuar); capacidade enquanto liberdade de bem-estar (well-being freedom) - entendida como liberdade de alguém para realizar aquelas coisas que são constitutivas do seu bem-estar, ${ }^{45}$ ou seja, no sentido de ver-se livre de privações (p. ex.: estar livre da fome).

Sen centraliza seu olhar sobre o papel das capacidades na demarcação de um espaço para a análise do aumento da qualidade de vida das pessoas, por acreditar que no espaço das capacidades, questões relativas à igualdade social e desigualdade são melhor levantadas. ${ }^{46}$

Embora criticado por priorizar a liberdade em suas diversas formas de expressão, relegando a igualdade para um segundo plano, ${ }^{47}$ Sen esclarece que igualar a propriedade de recursos ou parcelas de bens primários não necessariamente iguala as liberdades usufruídas por pessoas diferentes, já que pode haver variações significativas na conversão de recursos e bens primários em liberdades. $^{48}$

Assim, transcendendo os igualitarismos (de recursos e/ou utilidade), Sen entende que a igualdade intrinsecamente dependente da liberdade de escolha e das oportunidades se concretiza quando as pessoas dispõem, nas mesmas condições, do instrumental que precisam para alcançar suas aspirações e livremente escolher o que valorizam em suas vidas. Note-se que para Sen ter

\footnotetext{
${ }^{4}$ NUSSBAUM, Martha C. Capabilities as Fundamental Entitlements: Sen and Social Justice. Disponível em: https://philpapers.org/archive/NUSCAF.pdf. Acesso em: 25 maio 2018. p. 15.

45 NUSSBAUM, Martha C. Capabilities as Fundamental Entitlements: Sen and Social Justice. Disponível em: https://philpapers.org/archive/NUSCAF.pdf. Acesso em: 25 maio 2018. p. 104.

${ }^{46}$ No original: "Sen has also insisted that it is in the space of capabilities that questions about social equality and inequality are best raised.". (Cf. NUSSBAUM, Martha C. Women and Human Development: the Capabilities Approach. Cambridge: Cambridge University Press, 2001. p. 12.).

${ }^{47}$ Cohen ao criticar Sen afirma que ao se valer "[...] de uma métrica para mensuração do bem-estar que recai entre os bens primários e a utilidade [...]. Ele chama aquilo "capacidade": o que está faltando em todo esse modelo é uma noção de 'capacidade básicas'; uma pessoa estar apta a fazer certas coisas básicas [...]'. Ao comentar sobre a falta das capacidades básicas, o autor traz à tona um questionamento direcionado à pauta da igualdade na teoria de Sen. G. A. Cohen, além de favorável à igualdade enquanto métrica entende que Sen não apenas destaca em sua teoria a liberdade como valor fundamental, como deixa o problema da igualdade para segundo plano. (Cf. COHEN, G. A. Equality of What/ On Welfare, goods and Capabilities. In: NUSSBAUM, Martha C.; SEN, Amartya. (Orgs.). The Quality of Life. Oxford: Clarendon Press, 1993.

${ }^{48}$ SEN, Amartya. Desenvolvimento como liberdade. Trad. Laura Teixeira Motta. São Paulo: Companhia das Letras, 2010. p. 71.
} 
capacidade significa ter liberdade, sendo a igualdade, nesse caso, um elemento subjacente ao exercício da liberdade. ${ }^{49}$

Nussbaum levanta duas críticas em relação à preocupação extenuante de Sen em relação à liberdade. Primeiramente, afirma não ter claro para si que a promoção da liberdade consiste num "projeto político coerente", pois, como algumas liberdades limitam o exercício de outras - por exemplo, a liberdade dos negócios poluírem o ambiente limita a liberdade dos cidadãos desfrutarem de um ambiente despoluído; a liberdade dos proprietários de manter suas terras limita projetos de reforma fundiária que podem ser primordiais para as liberdades de pessoas mais pobres sua teoria deveria ter dito algo acerca do sentido e da limitação dessa liberdade que busca proteger, e sobre como resolver conflitos envolvendo liberdades diversas. ${ }^{50}$

Insiste ainda que qualquer projeto político que irá proteger o igual valor de certas liberdades básicas para os pobres e para melhoria de suas condições de vida precisa dizer diretamente que algumas liberdades são centrais para propósitos políticos e outras distintamente não o são. ${ }^{51}$ Assim, mesmo tendo a liberdade genericamente considerada como ponto focal, isso não seria incompatível com o estabelecimento de um rol de liberdades definidas como relevantes - a exemplo do que verifica na lista das capacidades.

Por fim, embora endosse os argumentos de Sen, Nussbaum entende que são insuficientes para se pensar em justiça social, pois, apesar de fornecer uma noção geral do que as sociedades precisam alcançar, não dá pistas do que seria um patamar mínimo de capacidades a ser atingido por sociedades que se dizem justas. ${ }^{52}$

Nussbaum, por sua vez, trabalha as capacidades num recorte normativo, sob a perspectiva do desenvolvimento de princípios constitucionais centrais que assegurem aos cidadãos um patamar mínimo de realização, por entender que em certas áreas principais do funcionamento humano, a necessária condição de justiça para a estruturação de uma política pública é conferir aos cidadãos certo nível básico de capacidade. ${ }^{53}$

Assim, sob a ótica das capacidades, se as pessoas têm sistematicamente ficado abaixo deste mínimo em qualquer das principais áreas protegidas, tem-se uma situação injusta e trágica que necessita, portanto, urgente atenção, ${ }^{54}$ ainda que não haja quaisquer outros problemas ocorrendo nas demais áreas que asseguram a manutenção da condição humana.

O enfoque das capacidades, para além da preocupação com bens, recursos ou utilidade que, diga-se de passagem, não são elementos que ignora ou desconsidera reconhece, a partir do olhar atento às circunstâncias externas que interferem no exercício da liberdade, que a justiça está em se garantir um nível mínimo de capacidades a todos os indivíduos, e em todas as áreas, para que possam sentir-se livres para alcançar a vida que valorizam.

Essa preocupação com fatores de ordem social, cultural, psicológica, de raça, de gênero etc. que exercem influência sobre a forma como as pessoas usufruem de sua liberdade (enquanto

\footnotetext{
${ }^{49}$ REICHER, Stella Camlot. Capacidades e direitos humanos: uma análise conceitual sob a ótica de Martha Nussbaum. 2009. Tese de Doutorado. Universidade de São Paulo. 2009. p. 44.

${ }^{50}$ NUSSBAUM, Martha C. Capabilities as Fundamental Entitlements: Sen and Social Justice. Disponível em: https://philpapers.org/archive/NUSCAF.pdf>. Acesso em: 25 maio 2018. p. 15.

51 NUSSBAUM, Martha C. Capabilities as Fundamental Entitlements: Sen and Social Justice. Disponível em: https://philpapers.org/archive/NUSCAF.pdf>. Acesso em: 25 maio 2018. p. 15.

52 NUSSBAUM, Martha C. Capabilities as Fundamental Entitlements: Sen and Social Justice. Disponível em: https://philpapers.org/archive/NUSCAF.pdf. Acesso em: 25 maio 2018. p. 02.

53 NUSSBAUM, Martha C. Women and Human Development: The Capabilities Approach. Cambridge: Cambridge University Press, 2001. p. 70.

${ }^{54}$ NUSSBAUM, Martha C. Women and Human Development: The Capabilities Approach. Cambridge: Cambridge University Press, 2001. p. 71.
} 
capacidade de ser livre para e livre de) é um aspecto importante que diferencia a abordagem das capacidades de outros modelos de avaliação de qualidade de vida e desenvolvimento, na medida em que revela uma intensa preocupação com o indivíduo e com o bem-estar individual e possibilita a criação de um espaço imaginativo que permite a cada um sonhar com todas as possibilidades, com tudo aquilo que qualquer indivíduo, em sua singularidade humana, ${ }^{55}$ possa valorizar.

No entanto, como seu trabalho não reside na busca de uma igualdade completa de capacidades, mas tão somente um patamar mínimo indispensável, ela própria reconhece que sua abordagem não poderia ser reconhecida como uma teoria integral, mas apenas como uma teoria parcial de justiça, ${ }^{56}$ já que não aborda, por exemplo, como a justiça deveria tratar desigualdades verificadas acima desse nível mínimo. ${ }^{57}$

Trata-se de um modelo que encampa o conteúdo dos principais direitos humanos ${ }^{58}$ reconhecidos - assim denominados basic entitlements associada a uma racionalidade de sentimentos - tais como a reciprocidade, e a afiliação sendo, por isso mesmo, compatível com diferentes visões sobre como resolver assuntos de justiça e de distribuição que podem surgir quando todos os cidadãos já estiverem acima desse nível mínimo. ${ }^{59}$

Cabe aqui esclarecer o sentido que se confere à expressão basic entitlements. Nussbaum afirma que dizer que as pessoas têm direito a alguma coisa é dizer que elas têm um urgente direito

\footnotetext{
55 NUSSBAUM, Martha C. Women and Human Development: The Capabilities Approach. Cambridge: Cambridge University Press, 2001. p. 71.

${ }^{56}$ A autora defende que o enfoque das capacidades ainda não pode ser considerado uma teoria completa de justiça em virtude de uma série de lacunas que ainda precisam ser melhor elaboradas, como por exemplo, questões atinentes à métrica de que se utiliza, à linha divisória entre o que é responsabilidade coletiva e individual, como e por quem as decisões são tomadas, entre outros aspectos. Cf. ROBEYENS, Ingrid. Capabilities and Theories of Social Justice. p.
} 16-18. Disponível em: http://www.ingridrobeyns.nl/Downloads/feltrinelli.pdf. Acesso em: 30 maio 2018.

${ }^{57}$ NUSSBAUM, Martha C. Frontiers of Justice: Disability, Nationality e Species Members. Harvard University Press, 2007. p. 75.

${ }^{58}$ Destaque-se por relevante, que os direitos humanos segundo Amartya Sem sofrem três críticas em relação ao edifício intelectual dos direitos humanos, bem como crítica da legitimidade, crítica da coerência e crítica cultural "Há, primeiro, o receio de que os direitos humanos confundam consequências de sistemas legais, que conferem às pessoas direitos bem definidos, com princípios pré-legais que não podem realmente dar a uma pessoa um direito juridicamente exigível. Essa é a questão da legitimidade das reivindicações de direitos humanos: como os direitos humanos podem ter qualquer status real exceto por meio de pretensões que sejam sancionados pelo Estado, como a suprema autoridade legal? Nessa concepção, os seres humanos nascem na natureza sem direitos humanos tanto quanto nascem sem roupa; os direitos teriam de ser adquiridos por meio da legislação, como as roupas são adquiridas de alguém que a faz. As roupas não existem antes de serem feitas, do mesmo modo como não existem direitos pré-legislação. Denominarei essa linha de argumentação critica da legitimidade.

A segunda linha de crítica relaciona-se à forma assumida pela ética e pela política dos direitos humanos. Nessa concepção, direitos são pretensões que requerem deveres correlatos. Se a pessoa A tem um direito a certo $x$, deve existir algum agente, digamos B, que tenha o dever de fornecer $x$ a A. Não sendo reconhecido esse dever, os direitos alegados, segundo esse ponto de vista, só podem ser vazios. Julga-se que isso representa um problema formidável para os direitos humanos cheguem a ser considerados direitos. Pode ser muito bonito, diz esse argumento, afirmar que todo ser humano tem direito a alimento ou a serviços médicos, mas, se não houver sido caracterizado nenhum dever específico de um agente, esses direitos não podem realmente "significar" grande coisa. Os direitos humanos, nessa concepção, são sentimentos comoventes, mas também são rigorosamente incoerentes. Dessa perspectiva, essas pretensões seriam mais adequadamente vistas não tanto como direitos, e sim como nós na garganta. Denominarei esse ponto de vista critica da coerência.

A terceira linha de ceticismo não assume exatamente uma forma legal e institucional, mas vê os direitos humanos como pertencentes ao domínio da ética social. A autoridade moral dos direitos humanos, por essa perspectiva, depende da natureza de éticas aceitáveis. Contudo, essas éticas são realmente universais? [...] não existem valores universais (ex. valores asiáticos). Chamarei essa vertente de crítica cultural. [...] Reconhecer a diversidade encontrada em diferentes culturas é muito importante no mundo contemporâneo". SEN, Amartya. Desenvolvimento como liberdade. Trad. Laura Teixeira Motta. São Paulo: Companhia das Letras, 2010. p. 292-298.

${ }^{59}$ NUSSBAUM, Martha C. Frontiers of Justice: Disability, Nationality e Species Members. Harvard University Press, 2007. p. 75. 
a isso. Nesse sentido, ao argumentar que as capacidades humanas básicas são, para além de objetivos sociais desejados, entitlements urgentes embasados na justiça, ${ }^{60}$ no enfoque das capacidades a idéia de entitlement não indica apenas um direito reconhecido - já que em inglês, os direitos positivados são chamados de rights. Trata-se, portanto, de expressão que designa a idéia de ter direito a alguma coisa.

Nessa direção, o enfoque das capacidades entende que a base para o surgimento de demandas é a simples existência da pessoa enquanto ser humano - e não a posse atual de um conjunto de capacidades básicas rudimentares, que teria origem - sem adentrar no mérito de discussões sobre o início da vida - quando do nascimento da pessoa no seio de uma comunidade humana. ${ }^{61}$

Essa noção de direitos enquanto entitlements guarda estreita relação com o fato de que cada indivíduo é um fim em si mesmo, e por isso não deve ser utilizado para a realização de fins alheios, sendo a sua dignidade assegurada somente quando presentes todos os pré-requisitos para que se possa viver uma vida que seja realmente humana ao invés de subumana, uma vida que merece a dignidade do ser humano". ${ }^{2}$

A expressão entitlements deve então ser compreendida como sendo "direito a" alguma coisa e nesse sentido, como algo que pode ser livremente pleiteado pelas pessoas porque lhes pertence de forma inata. Esse entendimento nos remete à noção de direitos subjetivos aqueles que mesmo não reconhecidos por escrito, podem ser sempre demandados, à medida que refletem a própria liberdade de agir da cada um.

É interessante notar que o exercício desse direito subjetivo ou "direito a" alguma coisa também se manifesta no poder de exigir dos que foram incumbidos do dever de resguardo desse direito, ou de quaisquer terceiros, que ajam no sentido de assegurá-lo para que o indivíduo se veja livre de quaisquer males e, ao mesmo tempo, livre para levar a vida que quiser.

Embora esse agir que o titular do direito subjetivo basic entitlement exige daquele que tem o dever de assegurar esse direito, se manifeste por meio de uma ação (p.ex., prover alimentos) ou de uma omissão ou não fazer (p.ex., não interferir no exercício de práticas religiosas), é certo que em qualquer dos dois casos, sempre um agir positivo deverá ser adotado.

Veja-se que mesmo nos casos de não interferência, como por exemplo, na garantia do exercício de liberdade religiosa, para além de não interferir, é preciso que as demais capacidades necessárias à plena fruição desse direito sejam igualmente asseguradas.

Portanto, a noção de entitlements nos conduz ao reconhecimento de que a mera dicção de direitos, sejam estes positivados ou reconhecidos pelo costume, não significa que estão assegurados, não se realizando somente a partir da noção de liberdade negativa - ou seja, pela simples não interferência estatal na vida particular das pessoas.

Em resumo, a expressão entitlement designa na teoria das capacidades a noção de direito em sua acepção subjetiva, como possibilidade de exigir ou autorização para demandar a efetiva garantia de todas as condições (materiais e institucionais) necessárias à manutenção dos elementos que minimamente asseguram uma vida plenamente humana, em oposição ao conceito de rights

\footnotetext{
${ }^{60}$ NUSSBAUM, Martha C. Frontiers of Justice: Disability, Nationality e Species Members. Harvard University Press, 2007. p. 290.

${ }^{61}$ NUSSBAUM, Martha C. Frontiers of Justice: Disability, Nationality e Species Members. Harvard University Press, 2007. p. 285.

${ }^{62}$ NUSSBAUM, Martha C. Frontiers of Justice: Disability, Nationality e Species Members. Harvard University Press, 2007. p. 278.
} 
estes sim compreendidos em sua dimensão objetiva, como direitos reconhecidos no papel ou positivados.

Um aspecto interessante e que decorre da importância conferida a esses direitos básicos, refere-se à posição que os deveres ocupam na abordagem das capacidades. Para

alguns autores, o ponto de partida do desenvolvimento dessa abordagem deveria residir na noção de deveres.

De acordo com essa linha de pensamento, o raciocínio a respeito dos deveres se desenvolve da seguinte forma: se pensar-se sobre o que tem-se o dever de fazer, e de não fazer, em virtude de, e para os seres humanos, esta reflexão nos informa sobre o que o destinatário tem direito de receber.

Por outro lado, há quem entenda que deve-se pautar pelos "direitos a determinada coisa" que são assegurados às pessoas. $\mathrm{O}$ discurso aqui empregado obedece à seguinte lógica: considerase o que as pessoas têm direito a receber, e, mesmo antes de poder dizer quem deve ter os deveres, conclui-se que há esses deveres, e que tem-se certo tipo de obrigação coletiva de assegurar que as pessoas recebam o que tem direito.

Na realidade, como a noção de dever não pode surgir do nada e nem mesmo ser definida enquanto não se tem clareza sobre o que é devido, parece correto reconhecer que os deveres sucedem a percepção das necessidades humanas.

Os deveres, portanto, só existem a partir do momento em que define-se que as pessoas têm certas necessidades básicas, que pontua-se que necessidades são essas e que afirma-se a relevância de que tais necessidades sejam garantias por todos e quaisquer meios inclusive atribuindo às pessoas poderes para exigir o provimento dessas necessidades mínimas a fim de que as pessoas possam se resguardar de injustiças e manter uma vida plenamente humana.

Feitas essas considerações preliminares, veja-se como as capacidades foram organizadas nessa teoria, tendo como premissa o reconhecimento do ser humano como ser moral e racional, que possui como fonte primária de sua riqueza a habilidade de planejar sua vida de acordo com os fins que pretende alcançar. ${ }^{63}$

Conforme salienta Nussbaum, a teoria das capacidades parte da intuição básica de que algumas habilidades humanas são dotadas de dignidade e valor por possibilitarem a realização de diversas funcionalidades, sendo tidas como demandas morais que ensejam deveres políticos e sociais correlatos.

A base desta construção axiológica não reside em nenhuma teoria metafísica ou teológica, mas sim, num senso de tragédia que cruza e atravessa fronteiras culturais, ou seja, num consenso universal acerca dos elementos mínimos capazes de assegurar a manutenção de uma vida humana. ${ }^{64}$

Nessa direção, apenas às capacidades humanas consideradas mais relevantes se atribui algum valor moral, exigindo, portanto, cuidado. As capacidades destituídas de valor moral, como por exemplo, a capacidade para ser cruel, para discriminar as pessoas com base na raça, gênero, etc. e para poluir o ambiente, entre tantas outras não ensejariam qualquer proteção. ${ }^{65}$

\footnotetext{
${ }^{63}$ REICHER, Stella Camlot. Capacidades e direitos humanos: uma análise conceitual sob a ótica de Martha Nussbaum. 2009. Tese de Doutorado. Universidade de São Paulo. 2009. p. 49.

${ }^{64}$ REICHER, Stella Camlot. Capacidades e direitos humanos: uma análise conceitual sob a ótica de Martha Nussbaum. 2009. Tese de Doutorado. Universidade de São Paulo. 2009. p. 50.

${ }^{65}$ REICHER, Stella Camlot. Capacidades e direitos humanos: uma análise conceitual sob a ótica de Martha Nussbaum. 2009. Tese de Doutorado. Universidade de São Paulo. 2009. p. 49.
} 
A partir dessa estrutura lógica, as capacidades são classificadas em três distintas categorias, a saber: Capacidades Básicas: são habilidades rudimentares para se levar uma vida digna, com as quais as pessoas vêm ao mundo; são aquelas que precisam suporte, especialmente do mundo político, para serem desenvolvidas e efetivadas.

São os equipamentos inatos necessários ao desenvolvimento de outras capacidades que às vezes estão mais ou menos prontas para gerar funcionalidades - como a capacidade de ver e ouvir; e outras, que não podem ser imediatamente convertidas em funcionalidades - como a habilidade para andar e falar. Em geral, são capacidades que encontram suporte na educação, no apoio da família e de outras instituições.

Capacidades Internas: são estados da própria pessoa que se ligam à idéia de estado de maturidade; são em si mesmas capacidades que muitas vezes independem de fatores externos para concretizarem funcionalidades. Por exemplo, as crianças, pelo simples fato de crescerem, chegam à puberdade e tornam-se aptos ao exercício da funcionalidade sexual.

Capacidades Combinadas: resultam da combinação de capacidades internas com condições externas que possibilitam o exercício de uma funcionalidade. É o caso, por exemplo, da liberdade de expressão. Considere-se uma pessoa adulta que possui as capacidades internas necessárias para o exercício dessa liberdade. No entanto, por viver num regime não democrático, não dispõe de condições externas que lhe permitam exercitar essa liberdade, razão pela qual, dizemos que não dispõe das capacidades combinadas necessárias ao pleno exercício da liberdade de expressão.

Por fim, priorizando as capacidades combinadas, a abordagem das capacidades ressalta a importância conjunta de circunstâncias materiais e sociais e como estas interferem no treinamento e no desenvolvimento das capacidades, bem como o importante papel que a liberdade tem dentro desta construção, conduzindo portato ao estabelecimento de direitos verdadeiramene humanos.

\section{CONSIDERAÇÕES FINAIS}

Assim, ao reconhecer que todas as capacidades elencadas na lista possuem valor em si mesmas e que uma vida plenamente humana depende de um patamar mínimo de realização em cada uma dessas áreas, a abordagem das capacidades rejeita a possibilidade de fungibilidade das capacidades - a compensação da falta de uma capacidade pela realização em maior quantidade de alguma outra.

Nesse sentido, ao limitar o tipo de troca que razoavelmente poderá ser realizada, e a aplicabilidade das análises quantitativas de custo-benefício, a abordagem impede barganhas envolvendo capacidades julgadas mais ou menos importantes, reafirmando assim a indivisibilidade dos direitos humanos - pois reconhece que direitos civis e políticos, econômicos, sociais e culturais são igualmente relevantes para a plena realização humana.

A construção das capacidades parte das liberdades fundamentais e da análise dos fatores materiais e sociais, internos e externos que interferem na satisfação de certas funcionalidades. Em seguida, passa pela compreensão do que o indivíduo está em condições de fazer para então determinar em que áreas, como condição de justiça, um nível mínimo de capacidades deve ser promovido.

Desta forma, é a partir da consciência de que algumas capacidades são tão centrais na vida de qualquer ser humano que sua ausência determinaria basicamente a ausência de uma vida humana e de que certas privações são reconhecidamente terríveis, no âmbito de qualquer cultura - não obstante os entendimentos que cada uma pode ter em relação ao mundo que Martha Nussbaum 
justifica a possibilidade de enumeração desses elementos centrais que poderiam comandar um consenso intercultural.

A lista é, portanto, um conjunto mínimo de valores necessários à realização da justiça social que deve ser garantido por toda e qualquer sociedade que se diz justa, independentemente do nível de riqueza que ostente, que funciona como elemento central de toda abordagem dos Direitos Humanos.

\section{REFERÊNCIAS}

ASSIS, Machado de. Histórias da meia noite. Rio de Janeiro: B. L. Garnier, Livreiro-Editor do Instituto Histórico, 1873.

BUGLIONE, Samantha; SCHULTE, Neide Köhler. "Capacidades” como postulado para ampliar a comunidade jurídica e moral na proposta de Martha Nussbaum. R. Inter. Interdisc.

INTERthesis, Florianópolis, v.10, n.1, p. 212-236, Jan./Jul. 2013.

BÜHRING, Marcia Andrea. Direitos Humanos e Fundamentais: Para além da Dignidade da Pessoa Humana, volume 1. Porto Alegre, RS: Editora Fi, 2014.

CAMPS, Victoria. El gobierno de las emociones. Barcelona: Herder, 2011.

COHEN, G. A. Equality of What/ On Welfare, goods and Capabilities. In: NUSSBAUM, Martha C.; SEN, Amartya. (Orgs.). The Quality of Life. Oxford: Clarendon Press, 1993.

ELSTER, Jon. Sobre las pasiones: emoción, adicción y conducta humana. Barcelona: Paidós, 2001.

ELSTER, Jon. Alquimias de la mente: la racionalidad y las emociones. Barcelona: Paidós, 2002.

FELIPE, Sonia T. Agência e paciência moral: razão e vulnerabilidade na constituição da comunidade moral.Ethic@ - Revista Internacional de Filosofia Moral, Florianópolis, v. 6, n. 4, p. $65-75,2007$.

LOBATO, Josefina Pimenta. Antropologia do amor: do Oriente ao Ocidente. Belo Horizonte: Autêntica, 2012.

MACINTYRE, Alasdair. Justiça de quem? Qual racionalidade? São Paulo: Loyola, 1991.

NUSSBAUM, Martha C. Love's Knowledge: essays on Philosophy and Literature. New York: Oxford University Press, 1990.

NUSSBAUM, Martha C. Capability and Well-Being. In: NUSSBAUM, Martha C.; SEN, Amartya. (Orgs.). The Quality of Life. Oxford: Clarendon Press, 1993.

NUSSBAUM, Martha C. La fragilidad del bien: fortuna y ética en la tragedia y la filosofía griega. Trad. de Antonio Ballesteros. Madrid: Visor, 1995. 
NUSSBAUM, Martha C. Women and Human Development: The Capabilities Approach. Cambridge: Cambridge University Press, 2001.

NUSSBAUM, Martha C. Las mujeres y el desarrollo humano: el enfoque de las capacidades. Barcelona: Herder, 2002.

NUSSBAUM, Martha C. Capacidades como Titulaciones Fundamentales: Sen y la Justicia Social. Bogotá, Colombia: Universidad del Externado de Colombia, 2005.

NUSSBAUM, Martha C. The Supreme Court Term 2006 -Foreword: Constitutions and Capabilities: "Perception" against Lofty Formalism. Harvard Law Review. Disponível em: https://cdn.harvardlawreview.org/wp-content/uploads/pdfs/nussbaum.pdf. Acesso em: 25 maio 2018.

NUSSBAUM, Martha C. Frontiers of Justice: Disability, Nationality e Species Members. Harvard University Press, 2007.

NUSSBAUM, Martha C. Paisajes del pensamiento: la inteligencia de las emociones. Barcelona: Paidós, 2012.

NUSSBAUM, Martha C. Fronteiras da justiça: deficiência, nacionalidade, pertencimento à espécie. Trad. de Susana de Castro. São Paulo, 2013.

NUSSBAUM, Martha C. Capabilities as Fundamental Entitlements: Sen and Social Justice. Disponível em: https://philpapers.org/archive/NUSCAF.pdf. Acesso em: 25 maio 2018.

NUSSBAUM, Martha C. El conocimiento del amor: ensayos sobre filosofía y literatura. Madrid: Antonio Machado Libros, 2016.

REICHER, Stella Camlot. Capacidades e direitos humanos: uma análise conceitual sob a ótica de Martha Nussbaum. 2009. Tese de Doutorado. Universidade de São Paulo. 2009.

ROBEYENS, Ingrid. Capabilities and Theories of Social Justice. p. 16-18. Disponível em: http://www.ingridrobeyns.nl/Downloads/feltrinelli.pdf. Acesso em: 30 maio 2018.

SEN, Amartya. Desenvolvimento como Liberdade. Tradução Laura Teixeira Motta. São Paulo: Companhia das Letras, 2000.

SEN, Amartya. Desenvolvimento como liberdade. Trad. Laura Teixeira Motta. São Paulo: Companhia das Letras, 2010.

SEN, Amartya. Desenvolvimento como liberdade. São Paulo: Companhia de Letras, 2013.

SILVESTRE, Ana Carolina Faria. As emoções racionais e a realização prática do direito à luz da proposta de Martha Nussbaum: o papel das obras literárias e das emoções racionais no processo de tomada de decisão judicial. Revista de Estudos Jurídicos, Franca-SP, a. 15, n. 22, 2011. p. 285-307.

SOLOMON, Robert C. Ética emocional: una teoría de los sentimientos. Barcelona: Paidós, 2007. 